\title{
Variable Content of Double Minute Chromosomes Is Not Correlated with Degree of Phenotype Instability in Methotrexate-Resistant Human Cell Lines
}

\author{
JEFFREY MASTERS, BENNETA KEELEY, HELEN GAY, AND GIUSEPPE ATTARDI* \\ Division of Biology, California Institute of Technology, Pasadena, California 91125
}

Received 3 September 1981/Accepted 3 December 1981

\begin{abstract}
Several variants resistant to $1.8 \times 10^{-4} \mathrm{M}$ DL-methotrexate (MTX) have been isolated from the human cell lines HeLa BU25 and $\mathrm{VA}_{2}-\mathrm{B}$ by exposing them to progressively increasing concentrations of the drug. A striking variability of phenotype and chromosome constitution was observed among the different variants. All resistant cell lines exhibited a greatly increased dihydrofolic acid reductase (DHFR) activity and DHFR content; however, the DHFR activity levels varied considerably among the variants, ranging between about 35 and 275 times the parental level. In the absence of selective pressure, the increased DHFR activity was unstable, and in all cell lines but one was completely lost over a period ranging in different variants between 25 and 200 days. The MTX-resistant cell lines showed anomalies in their chromosome constitution, which involved the occurrence of a duplicated set of chromosomes in most cells of some of the variants and the presence of double minute chromosomes in all cell lines. An analysis of the correlation of loss of double minute chromosomes and loss of DHFR activity in the absence of MTX has given results consistent with the idea that the double-minute chromosomes contain amplified DHFR genes. However, the most significant finding is that, in contrast to what has been reported in the mouse system, the recognizable double-minute chromosomes varied greatly in number in different variants without any relationship to either the level of DHFR activity or the degree of instability of MTX resistance in the absence of selective pressure. These and other observations point to the occurrence in the human MTX-resistant variants of another set of DHFR genes, representing a varied proportion of the total, which is associated with the regular chromosomes, and which may be unstable in the absence of selective pressure.
\end{abstract}

One of the most striking examples of the plasticity of the genome in animal cells is provided by the selective amplification of the genes coding for proteins with binding specificity for certain metabolic inhibitors or other harmful chemicals, as demonstrated in cultured mammalian cells resistant to such agents $(1,5,29)$. The best-studied case of this nature is the dihydrofolic acid reductase (DHFR) gene amplification in mammalian cells resistant to amethopterin (methotrexate, MTX) (1). In several human and experimental tumors and in cultured mouse and hamster cell lines, the development of the resistance to MTX has been found to be due to an increased cell content, up to several hundredfold, of the enzyme $(6,8,10-12,15,22,26,27$, 30 ). In cultured mammalian cell lines, the increased enzyme level has been shown to result from an increased rate of synthesis $(2,16)$, due to a selective amplification of the DHFR genes $(1,10,23,26)$ and to a parallel increase in the amount of DHFR mRNA $(1,9,18,23)$.
The biochemical investigations mentioned above have all been carried out in MTX-resistant cell lines of mouse or hamster origin. Recently, several MTX-resistant cell variants have been isolated in this laboratory from two different human cell lines, HeLa BU25 and VA $\mathrm{VA}_{2}-\mathrm{B}$; furthermore, the DHFRs have been isolated from HeLa BU25 cells and from two of the MTX-resistant derivatives and found to be indistinguishable in their physical and enzymatic properties (25). In this paper, we report that the human MTX-resistant cell lines isolated here exhibit a striking variability in phenotypic properties and chromosome constitution, even among sublines. Most significantly, they contain a highly variable number of double minute chromosomes which is not correlated with either the level or the stability of their resistance to MTX.

\section{MATERIALS AND METHODS}

Materials. Dihydrofolic acid and NADPH were obtained from Sigma Chemical Co. The MTX used as a 
selective agent for the drug-resistant variants was the DL-form from Sigma (consisting of $\sim 50 \%$ L-form).

Cell lines and methods of growth. The human cell line HeLa BU25, a mutant subline of HeLa S3 deficient in thymidine kinase activity (19), kindly provided by $S$. Kit, was grown in petri dishes in Eagle medium supplemented with $10 \%$ calf serum in the absence or presence of $25 \mu \mathrm{g}$ of bromodeoxyuridine (BUdR) per $\mathrm{ml}$. The human cell line $\mathrm{VA}_{2}-\mathrm{B}$, an azaguanine-resistant subclone of the simian virus 40-transformed line WI-18-VA $A_{2}$ (28), was grown in petri dishes in Eagle medium supplemented with $10 \%$ calf serum and $3 \mu \mathrm{g}$ of 8-azaguanine per $\mathrm{ml}$. The MTX-resistant variants of these two cell lines were grown in the media described above supplemented with $10 \%$ extensively dialyzed calf serum and various concentrations of DL-MTX as specified below.

Chromosome analysis. Cells were arrested in metaphase by treatment with $0.05 \mu \mathrm{g}$ of colchicine per $\mathrm{ml}$ for 3 to $5 \mathrm{~h}$. Karyotype analysis was performed as described previously (24).

Cell extraction preparation and enzyme assay. When a cell extract had to be prepared for enzyme assay, the cells were grown in the absence of MTX for 7 days before harvesting. The preparation of cell extracts and the enzyme assays were carried out essentially as described by Frearson et al. (13), except that in the enzyme assay the concentration of dihydrofolic acid was doubled. One unit of enzyme activity was defined as the amount of enzyme required to reduce $1 \mathrm{nmol}$ of dihydrofolic acid in $15 \mathrm{~min}$ at $21^{\circ} \mathrm{C}$.

Electrophoretic analysis. Electrophoresis of the cell extracts was carried out by using the Laemmli sodium dodecyl sulfate-polyacrylamide gel system (20) as previously described (25).

\section{RESULTS}

Isolation of MTX-resistant variants. HeLa BU25 cells previously grown in the absence or presence of BUdR $(25 \mu \mathrm{g} / \mathrm{ml})$ were exposed to $2 \times 10^{-8}$ or $5 \times 10^{-8} \mathrm{M}$ DL-MTX in BUdR-free (-BUdR) or BUdR-containing (+BUdR) medium, respectively; similarly, $\mathrm{VA}_{2}$-B cells were treated with either $5 \times 10^{-8}$ or $1 \times 10^{-7} \mathrm{M}$ DLMTX. Almost all of the cells treated with the above concentrations of MTX died in the first 2 weeks. Four colonies of BU25 (-BUdR) cells and four colonies of BU25 (+BUdR) cells resistant to $2 \times 10^{-8} \mathrm{M}$ DL-MTX, four colonies of BU25 (+BUdR) cells resistant to $5 \times 10^{-8} \mathrm{M}$ DL-MTX, four colonies of $\mathrm{VA}_{2}-\mathrm{B}$ cells resistant to $5 \times 10^{-8} \mathrm{M}$ DL-MTX, and four colonies of the same cell line resistant to $1 \times 10^{-7} \mathrm{M}$ DL-MTX were picked up by trypsinization 3 weeks after plating, and each was grown to a large culture. These clones, designated with a number indicating the plate and a letter indicating the clone picked up in each plate (for example, 10A, 10B, $10 C$, and 10D), were then exposed to increasing DL-MTX concentrations. Steps corresponding to two- to fourfold increases in MTX concentration were used, the final concentration being 1.8 $\times 10^{-4}$ M DL-MTX. Considerable cell death occurred after each increase; the surviving cells were grown for several weeks until no obvious cell death occurred before the next increase in MTX concentration in the medium was made. In the course of this process, each variant population was often subdivided into subpopulations, which were exposed to different schedules of increasing MTX concentrations, being thereafter maintained separate (designated by a progressive number following the clone letter designation, for example, 10B1, 10B2, 10B3). The whole process took between 7 and 11 months for different variants. Eleven variant cell lines, six derived from BU25 (-BUdR) cells, one derived from BU25 (+BUdR) cells, and four derived from $\mathrm{VA}_{2}-\mathrm{B}$ cells, which had acquired resistance to $1.8 \times 10^{-4} \mathrm{M}$ DL-MTX, were selected for further investigation (Table 1). Because of the continuous changes occurring in the MTX-resistant variants during growth in the presence of the drug, each variant is designated by its symbol and a subscript indicating the number of months of exposure to $1.8 \times 10^{-4} \mathrm{M}$ DL-MTX.

Growth characteristics of the MTX-resistant variants. All variants were found to grow more slowly in the presence of the drug than the parental cell lines grew in the absence of the drug. In particular, in the first few months after their adaptation to $1.8 \times 10^{-4} \mathrm{M}$ DL-MTX, their population doubling times varied between $35 \mathrm{~h}$ and more than $70 \mathrm{~h}$. A marked acceleration in growth rate occurred in the variants after prolonged exposure to the drug, their population doubling time approaching that of the parental cell lines. The slower growth rate of the MTXresistant variants was not due exclusively to the presence of the drug, as indicated by the observation that in several MTX-resistant variants, in the first 3 weeks after removal of the drug, the rate of cumulative growth was appreciably slower than that of the $\mathrm{VA}_{2}-\mathrm{B}$ parental cell line, gradually increasing thereafter.

Levels of DHFR in MTX-resistant and MTXsensitive cell lines. All of the MTX-resistant cell lines analyzed here exhibited an increased DHFR activity relative to the parental MTXsensitive cell lines (Table 1). The increase in DHFR levels in MTX-resistant variants, as measured within the first 10 months after their adaptation to $1.8 \times 10^{-4} \mathrm{M}$ DL-MTX, varied between about 35 and 275 times the levels found in the corresponding parental cell lines. It is interesting that a great variation in DHFR activity was observed also among sublines derived from the same original MTX-resistant clone (compare, for example, 7D2 and 7D3).

That the increase in DHFR activity in the MTX-resistant variants analyzed here reflected an increase in enzyme protein was shown by an electrophoretic analysis of the cell extracts. 
TABLE 1. DHFR activity and chromosome constitution of MTX-sensitive and MTX-resistant cell lines

\begin{tabular}{|c|c|c|c|c|c|c|c|}
\hline \multirow{2}{*}{ Cell line ${ }^{a}$} & \multirow{2}{*}{$\begin{array}{l}\text { DHFR } \\
\text { activity } \\
\text { (U/mg of } \\
\text { protein) }\end{array}$} & \multirow{2}{*}{$\begin{array}{l}\text { Relative } \\
\text { DHFR } \\
\text { activity }\end{array}$} & \multicolumn{2}{|c|}{$\begin{array}{l}\text { No. of days for decay } \\
\text { of DHFR activity in } \\
\text { MTX-free medium }\end{array}$} & \multicolumn{3}{|c|}{ Chromosome constitution $^{b}$} \\
\hline & & & To $50 \%$ & To $20 \%$ & Complement $^{c}$ & $\begin{array}{c}\text { No. of } \\
\text { chromosomes/ } \\
\text { cell }^{d}\end{array}$ & $\begin{array}{l}\text { No. of double } \\
\text { minutes per } \\
\text { celle }^{\text {e }}\end{array}$ \\
\hline $\begin{array}{r}\text { Parental } \\
\text { HeLa BU25 } \\
(- \text { BUdR) }\end{array}$ & $50.5 \pm 14.7$ & 1 & & & $1 \mathrm{~S}(100)$ & $59 \pm 1$ & $0.5(0-6)$ \\
\hline Variants & & & & & \multirow{3}{*}{$\begin{array}{l}1 S(100) \\
1 S(95) \\
2 S(5)\end{array}$} & & \\
\hline $10 \mathrm{~B} 1_{1}$ & 11,500 & 228 & 13 & 33 & & \multirow{2}{*}{$\begin{array}{l}57 \pm 2 \\
58 \pm 3 \\
93,111\end{array}$} & $19(0-132)$ \\
\hline $10 \mathrm{~B} 2_{1}$ & 9,100 & 180 & 21 & 38 & & & $28 \quad(0-130)$ \\
\hline $10 \mathrm{~B} 3_{3}$ & 13,800 & 273 & 16 & 31 & $\begin{array}{l}1 S(97) \\
2 S(3)\end{array}$ & $\begin{array}{c}57 \pm 4 \\
113\end{array}$ & $7(0-42)$ \\
\hline $10 C 1_{1}$ & 5,400 & 107 & 14 & 21 & $\begin{array}{l}1 S(73) \\
2 S(24) \\
3 S(3)\end{array}$ & $\begin{array}{c}55 \pm 1 \\
106 \pm 5 \\
166\end{array}$ & $75 \quad(4-257)$ \\
\hline $10 C 2_{1}$ & 5,200 & 103 & 47 & 86 & $\begin{array}{l}1 S(19) \\
2 S(81)\end{array}$ & $\begin{array}{r}55 \pm 5 \\
112 \pm 3\end{array}$ & $73(5-265)$ \\
\hline $10 C 3_{4}$ & 5,400 & 107 & 11 & 27 & $\begin{array}{l}1 S(8) \\
2 S(89) \\
4 S(3)\end{array}$ & $\begin{array}{c}56 \pm 2 \\
110 \pm 5 \\
210\end{array}$ & $219(46-475)$ \\
\hline $\begin{array}{r}\text { Parental } \\
\text { HeLA BU25 } \\
(+ \text { BUdR })\end{array}$ & $45.8 \pm 7.2$ & 1 & & & $\begin{array}{l}1 S(88) \\
2 S(12)\end{array}$ & $\begin{array}{r}58 \pm 1 \\
109 \pm 6\end{array}$ & $<0.3$ \\
\hline Variant & & & & & & & \\
\hline $14 D_{1}$ & 9,600 & 210 & 12 & 49 & $1 S(100)$ & $56 \pm 2$ & $26(0-100)$ \\
\hline $\begin{array}{l}\text { Parental } \\
\text { WI-18 VA2-B }\end{array}$ & $79.3 \pm 5.9$ & 1 & & & $\begin{array}{l}1 S(97) \\
2 S(3)\end{array}$ & $\begin{array}{c}68 \pm 2 \\
136\end{array}$ & $<0.3$ \\
\hline $\begin{array}{l}\text { Variants } \\
6 \mathrm{~A} 2_{8}\end{array}$ & 11,300 & 142 & 8 & 20 & $\begin{array}{l}\text { 1S (97) } \\
2 S(3)\end{array}$ & $\begin{array}{c}58 \pm 2 \\
115\end{array}$ & $182(34-841)$ \\
\hline $6 \mathrm{~A}_{2}$ & 7,300 & 92 & $34(18)^{f}$ & $240(39)^{f}$ & $\begin{array}{l}1 S(94) \\
2 S(6)\end{array}$ & $\begin{array}{l}56 \pm 1 \\
106,112\end{array}$ & $154(42-391)$ \\
\hline $\begin{array}{l}7 \mathrm{D} 2_{10} \\
7 \mathrm{D} 3_{2}\end{array}$ & $\begin{array}{r}11,400 \\
2,600\end{array}$ & $\begin{array}{r}144 \\
33\end{array}$ & $\begin{array}{l}18 \\
29\end{array}$ & $\begin{array}{l}90 \\
49\end{array}$ & $\begin{array}{l}2 S(100) \\
2 S(100)\end{array}$ & $\begin{array}{l}118 \pm 5 \\
122 \pm 5\end{array}$ & $\begin{aligned} 98 & (2-261) \\
120 & (9-348)\end{aligned}$ \\
\hline
\end{tabular}

${ }^{a}$ The subscripts in the symbols of the variants refer to the time when the analysis of DHFR activity was carried out.

${ }^{b}$ A total of 32 to 40 metaphase spreads were analyzed from each cell line within the first 6 months of maintenance in the presence of $1.8 \times 10^{-4} \mathrm{M}$ DL-MTX.

c Numbers within parentheses indicate the percentage of cells in each category.

${ }^{d}$ Average \pm standard deviation. Whenever only one or two metaphases were found in a given group, the individual values are reported.

e Since it was often difficult to identify the pairs of double minutes, especially when present in clusters, and since many of these elements appeared to be unpaired, the values reported here represent the mean and range of numbers of individual minutes per cell. From 45 to $74 \%$ of these minutes in different cell lines were in clearly recognizable pairs.

$f$ The numbers within parentheses represent the number of days calculated after subtracting the contribution of the relatively stable DHFR fraction to the individual values of overall DHFR activity (see Fig. 6B).

When equal amounts of protein were run through sodium dodecyl sulfate-polacrylamide gels, a band corresponding to a polypeptide with an $M_{\mathrm{r}}$ of $\sim 22,000$ comigrating with the purified DHFR (25) was observed in the extracts from the MTX-resistant variants, but not in those from the MTX-sensitive parental cell lines (Fig. 1). The extracts from $10 \mathrm{C} 2$ and $10 \mathrm{C} 3$ cells exhibited a band corresponding to DHFR which was clearly less pronounced than expected from 
their degree of resistance to MTX and from their DHFR activity (Table 1).

Behavior of increased DHFR activity in the MTX-resistant variants in the absence of MTX. All of the MTX-resistant cell lines, at the time when they were analyzed (within the first 10 months after their adaptation to $1.8 \times 10^{-4} \mathrm{M}$ DL-MTX), were unstable in the absence of MTX (Fig. 2 and Table 1); in fact, they gradually lost all or, in one case, most of their excess DHFR activity over periods ranging in different variants between 25 and 200 days. The cell line $6 \mathrm{A3}$ was unique in that it showed a biphasic loss of the excess DHFR activity: this declined to about $30 \%$ in 50 days, and thereafter decreased only very slowly to reach $\sim 10 \%$ in 400 days.

The loss of DHFR activity in the MTX-resistant variants in the absence of selection was accompanied by the loss of drug resistance. Thus, 10B3 cells which had been adapted to grow in the presence of $1.2 \times 10^{-4} \mathrm{M}$ DL-MTX (DHFR specific activity of $10.4 \times 10^{3} \mathrm{U} / \mathrm{mg}$ of protein) and were then maintained in the absence of the drug for 7 weeks (during which time the DHFR activity had dropped to $\sim 17 \%$ of the original value) gave only $0.3 \%$ survivors when challenged again with $1.2 \times 10^{-4} \mathrm{M}$ DL-MTX. These survivors showed the same level of en- zyme activity and, upon removal of the drug, the same degree of instability of MTX resistance as the original variants (Fig. 2).

Chromosome constitution. An analysis of the chromosome constitution of the MTX-resistant variants again revealed a marked variability. As illustrated in Table 1 and Fig. 3 and 4, which present the results of an analysis carried out within the first 6 months of maintenance of the variants in the presence of $1.8 \times 10^{-4} \mathrm{M}$ DLMTX, some cell lines exhibited predominantly a number of chromosomes close to that of their parental line, and others exhibited predominantly a duplicated number of chromosomes. This variability in chromosome number was also observed among sublines derived from the same original clone, as can be seen for the $10 \mathrm{C}$ sublines. One interesting observation is that, in all cases where no duplication of the chromosome complement occurred, the modal number of chromosomes in the MTX-resistant variants was lower than in the corresponding parental line (Table 1 and Fig. 3 and 4).

The most striking feature of the chromosome constitution of the MTX-resistant variants was the presence of double minute chromosomes, small, acentromeric chromosomal elements, which were absent or very rare in the parental

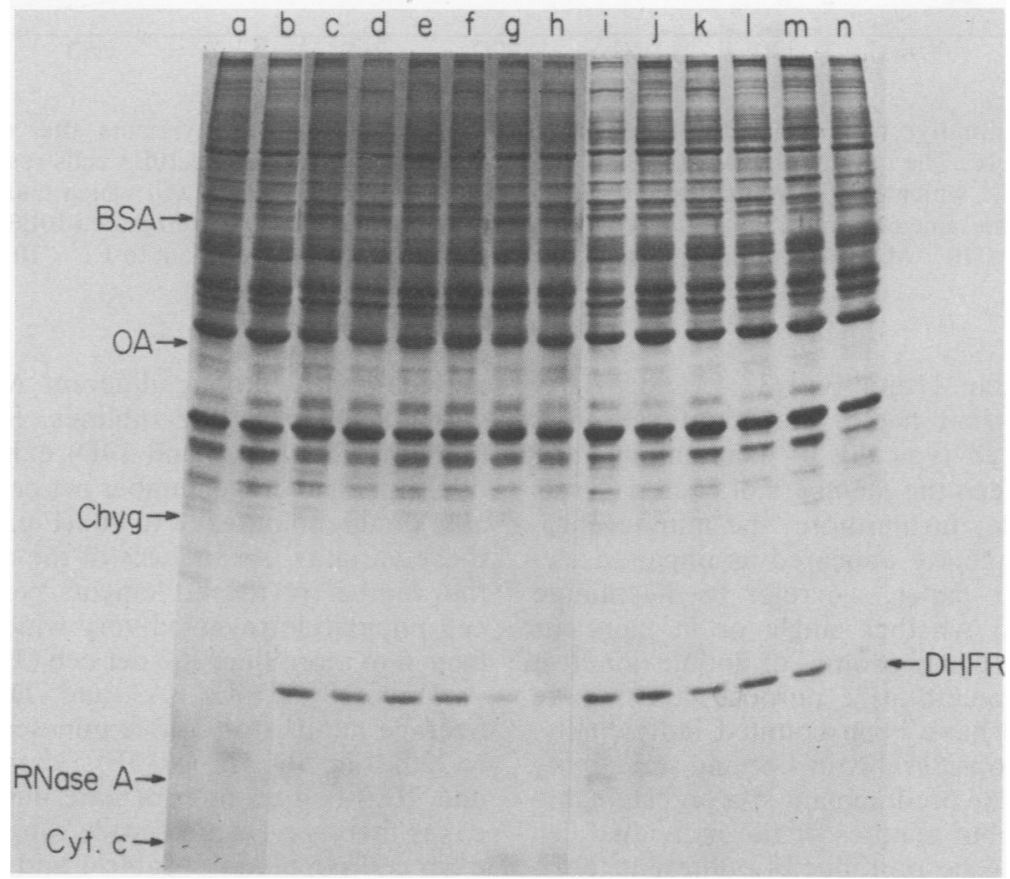

FIG. 1. Electrophoretic patterns in sodium dodecyl sulfate-polyacrylamide gel of the cell extracts from the parental lines and from the eleven MTX-resistant variants described in this work. Lanes: a, BU25 (-BUdR); b, BU25 (+BUdR); c, 10B1; d, 10B2; e, 10B3; f, 10C1; g, 10C2; h, 10C3; i, 14D; j, 6A2; k, 6A3; 1, 7D2; m, 7D3; n, $\mathbf{V A} \mathbf{A}-\mathbf{B}$. 

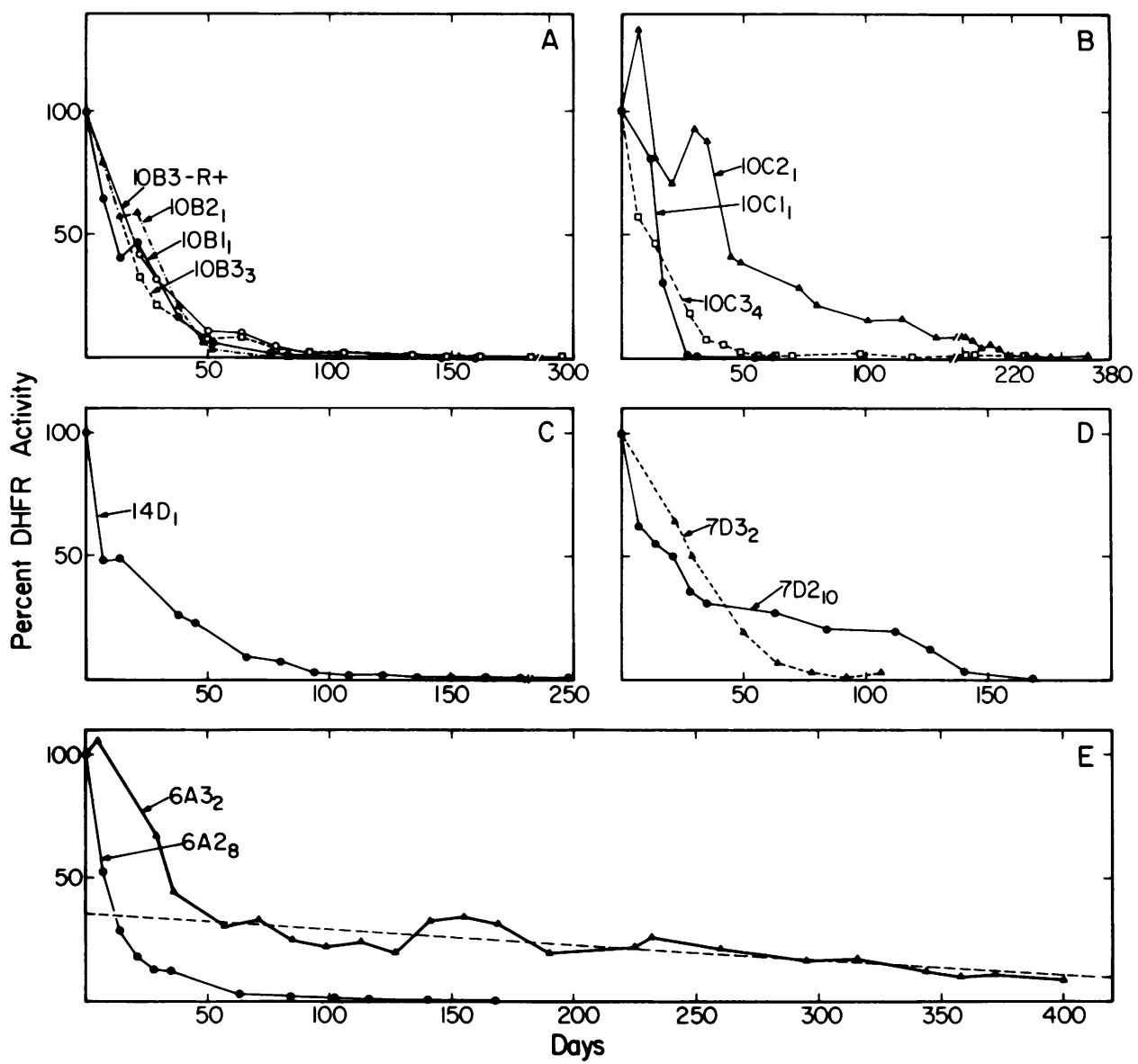

FIG. 2. Quantitative behavior of the DHFR activity of the MTX-resistant variants after removal of the selective pressure. The curve designated $10 \mathrm{~B} 3-\mathrm{R}+$ refers to partial revertants of $10 \mathrm{~B} 3$ cells resistant to $1.2 \times$ $10^{-4} \mathrm{M}$ DL-MTX which had been maintained for 7 weeks in drug-free medium and which had then survived reexposure to the same concentration of the drug. See text for details. The curve designated $10 B 3_{3}$ refers to cells resistant to $1.8 \times 10^{-4} \mathrm{M}$ DL-MTX; an identical curve was obtained for cells resistant to $1.2 \times 10^{-4} \mathrm{M}$ DL-MTX.

cell lines (Table 1 and Fig. 3, 4, and 5). As indicated by their name, the minute chromosomes appeared typically in pairs, though the distance between the members of each pair was highly variable; furthermore, the minute chromosomes frequently appeared as unpaired elements. In this paper, we refer to the minute chromosomes, whether single or in pairs, as double minute chromosomes or double minutes, although for quantitative purposes the minute chromosomes have been counted individually. They varied considerably in size and stainability with orcein. The predominant size and stainability of the double minutes of the individual cell lines tended to be reproducibly different (compare, for example, the double minutes of the 6A3 [Fig. 5D], 10C3 [Fig. 5E], and 7D3 [Fig. 5F] cells).

The number of double minute chromosomes varied greatly among different MTX-resistant variants, even among sublines. Some variants (10B1, 10B2, 10B3, and 14D) exhibited a relatively small average number per cell of recognizable double minutes ( 8 to 26 ) (Fig. 3 and $5 \mathrm{C}$ ); in these variants, an analysis of the distribution of the number of these elements per cell in each cell population revealed very wide fluctuations, from 0 to more than 100 per cell (Table 1 ). Other variants $(10 C 3,6 A 2,6 A 3$, and $7 D 3)$ had a large average number of double minutes per cell (120 to 220) (Fig. 5D, 5E, and 5F); others (10C1, 10C2 and 7D2) had an intermediate number. In both cases there was again a wide range of values in each cell population (Table 1 and Fig. 3 and 4). An examination of Table 1 shows the absence of any correlation in the various MTX-resistant variants between the average number of double minutes per cell and either the level of DHFR 


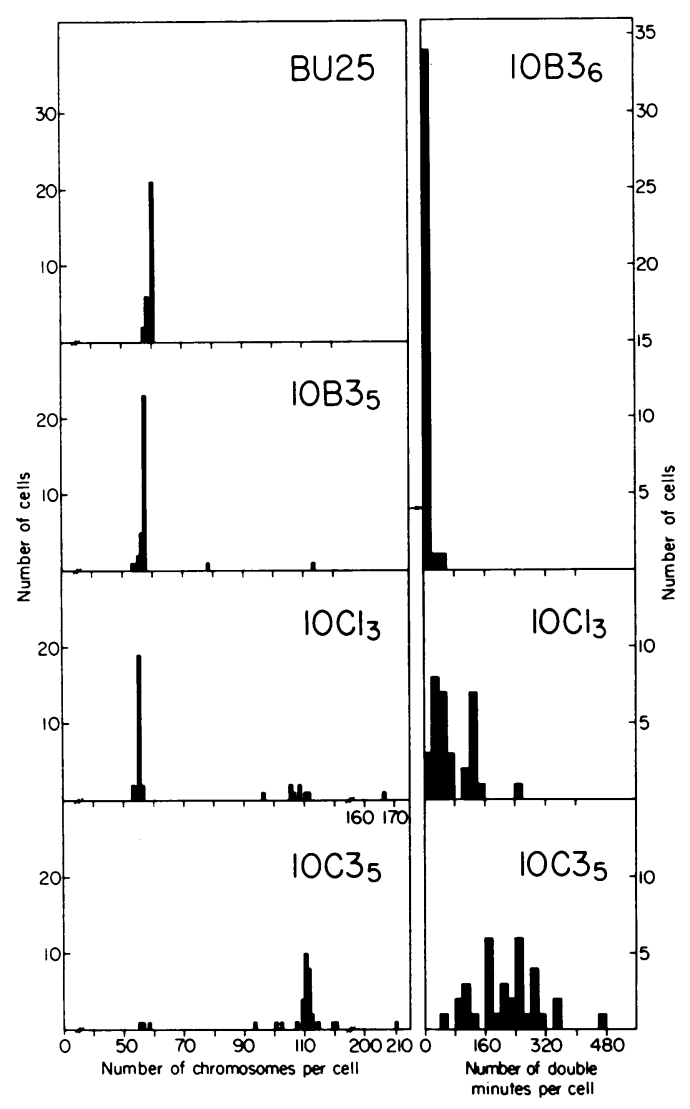

FIG. 3. Frequency distribution of number of chromosomes and number of double minutes per cell in the parental line BU25 (-BUdR) and its MTX-resistant derivatives $10 \mathrm{~B} 3,10 \mathrm{C} 1$, and $10 \mathrm{C} 3$. The arrow pointing to the ordinate axis in the uppermost right panel indicates the number of cells with no double minutes.

activity or the degree of instability of the increased DHFR level upon removal of MTX. Thus, the variants 10B1, 10B2, and 10B3 had a much smaller number of identifiable double minute chromosomes than did the 10C2 and 7D2 variants, yet they lost their excess DHFR activity much faster. The line $10 C 3$ had three times as many double minutes as the line $10 \mathrm{C} 1$, yet they lost their excess DHFR activity at the same rate.

Correlation of loss of double minute chromosomes and loss of DHFR activity upon removal of MTX. In mouse cell lines with unstable MTX resistance, a phenotype which in these cell lines appears to be correlated with the presence of double minute chromosomes, removal of the selective pressure leads to the loss of the double minutes (17). The same observation has been made here in the human MTX-resistant variant 6A3. When a suspension culture of these cells was grown for 6 days in the absence of MTX, the average number of double minute chromosomes dropped from 150 to 59 . These cells were then tested for the behavior of the DHFR activity and the number of double minute chromosomes upon further growth in the absence of MTX. Both DHFR activity and the number of double minutes declined progressively over the next 100 days (Fig. 6A). However, the kinetics of loss of enzyme activity, which paralleled that observed in cells grown on plates (Fig. 6A), differed significantly from the kinetics of loss of double minute chromosomes, which was likewise similar to that observed in cells grown on plates (data not shown). As mentioned above, the observed loss of DHFR activity from 6A3 cells was biphasic, with a phase of rapid loss superimposed upon a slow loss (Fig. 2). When the contribution of the slow decrease was subtracted from the individual values of DHFR activity, the resulting curve, which represented only the rapid loss of DHFR activity, showed an excellent agreement with the kinetics of loss of double minute chromosomes (Fig. 6B). One could calculate in this experiment that for every minute chromosome lost there was a decrease of about $80 \mathrm{U}$ of DHFR activity.

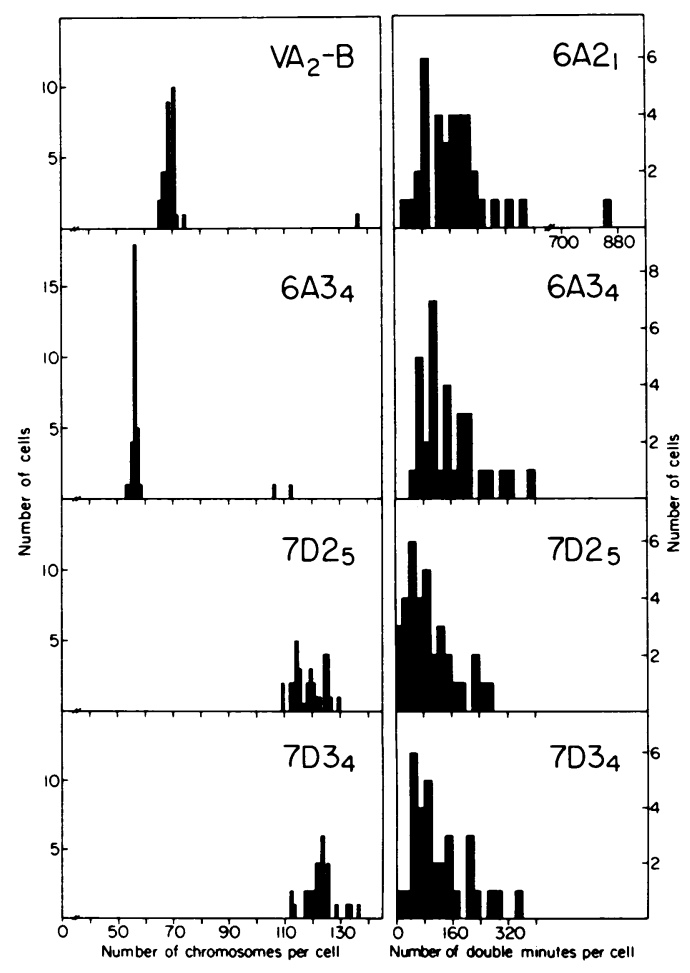

FIG. 4. Frequency distribution of number of chromosomes and number of double minutes per cell in the parental line $\mathrm{VA}_{\mathbf{2}}-\mathrm{B}$ and its MTX-resistant derivatives 6A2, 6A3, 7D2, and 7D3. 

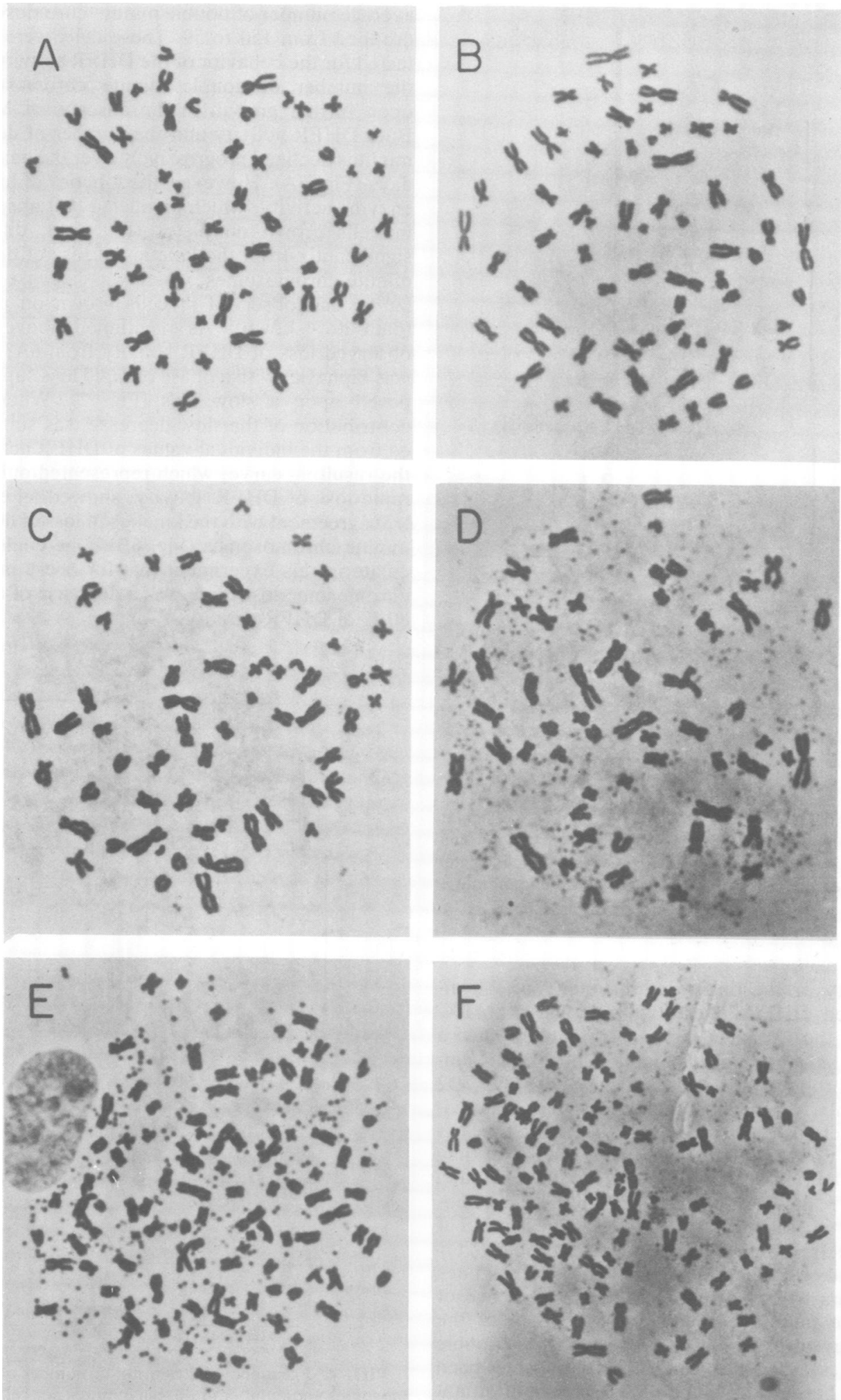

FIG. 5. Representative orcein-stained metaphase spreads from the BU25 (-BUdR) (A) and VA $A_{2}-B$ (B) parental cell lines and from the MTX-resistant variants $10 \mathrm{~B} 1_{11}(\mathrm{C}), 6 \mathrm{~A} 3_{4}(\mathrm{D}), 10 \mathrm{C} 3_{4}(\mathrm{E})$, and $7 \mathrm{D} 3_{4}(\mathrm{~F})$. 


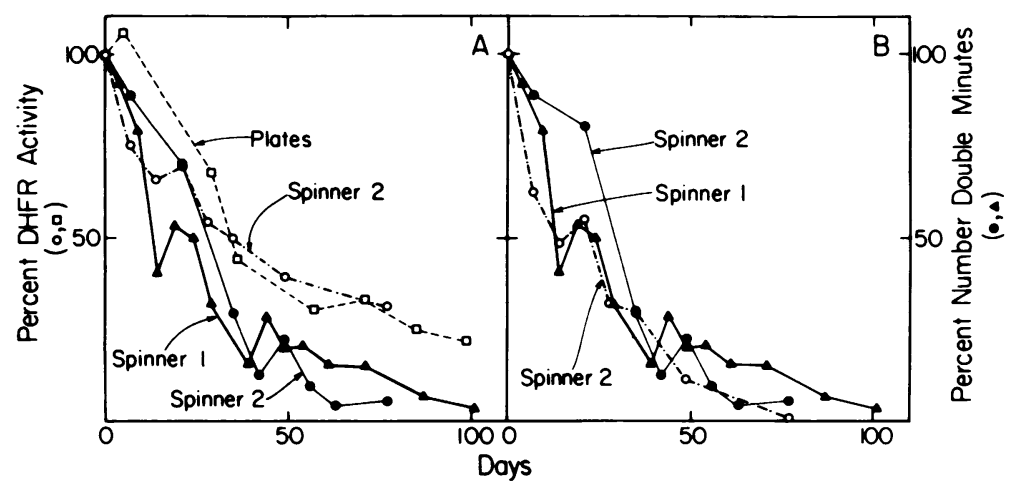

FIG. 6. Quantitative behavior of the DHFR activity and number of double minute chromosomes per cell in the variant $6 \mathrm{~A} 3$ after removal of the selective pressure. (A) Original data pertaining to cells grown in two spinner cultures and on plates. (B) DHFR data for one spinner culture, corrected by subtracting the contribution of the relatively stable DHFR fraction. See text for details.

\section{DISCUSSION}

In the present work, all the human cell variants isolated for their resistance to $1.8 \times 10^{-4} \mathrm{M}$ DL-MTX exhibited a greatly increased DHFR activity. Work reported elsewhere (C. Morandi, J. Masters, M. Mottes, and G. Attardi, J. Mol. Biol., in press) has revealed a large increase in the amount of DHFR-specific mRNA in the several variants which have been analyzed, derived from both the $\mathrm{VA}_{2}-\mathrm{B}$ and the HeLa BU25 parental lines. Furthermore, a genomic analysis of the $6 \mathrm{~A} 3,7 \mathrm{D} 3$, and $10 \mathrm{~B} 3$ cell lines, using probes derived from cloned DHFR cDNA, has shown a large increase in DHFR-specific DNA sequences as compared to the parental lines (unpublished observations). Therefore, it seems reasonable to conclude that a DHFR gene amplification has occurred in the human variants investigated here.

Although the resistance to high levels of MTX and the underlying basic mechanism appeared to be a common denominator of all of the variants investigated here, a striking diversity in growth behavior, relative level of DHFR activity or DHFR protein, chromosomal constitution, and degree of instability of the phenotype in the absence of selective pressure was observed among the various resistant cell lines analyzed in the first $\mathbf{1 0}$ months after their isolation and even among the sublines deriving from the same original MTX-resistant clones. Another aspect of the variability observed in the properties of the human MTX-resistant cell lines was the dynamic character of the changes detected, which was most obvious in their growth behavior and in their chromosome constitution.

In the cell lines $10 \mathrm{C} 2$ and $10 \mathrm{C} 3$, the detectable amount of DHFR protein was reproducibly much lower than that found in other variants exhibiting a similar increase in DHFR activity; this observation may indicate the occurrence in these variants of a structural gene mutation resulting in a protein product with a reduced affinity for MTX and an increased specific activity.

No completely stable MTX-resistant human variant has been found so far, in contrast to what has been reported for mouse and hamster cell lines. Although we have only limited data on this point, it does not seem that the above-mentioned difference merely reflects the fact the variants analyzed here represent relatively recent isolates. In fact, two of the variants (6A2 and 7D2), which were examined after 8 to 10 months of growth in the presence of $1.8 \times 10^{-4} \mathrm{M}$ DLMTX, exhibited an instability of phenotype comparable to that of the other variants. In some of the mouse MTX-resistant cell lines previously investigated by others, stability of the phenotype has been shown indeed to arise during prolonged growth in selective medium (17); however, other mouse and Chinese hamster cell lines have exhibited a stable resistance to the drug very early after their isolation $(10,26)$.

The most striking alterations observed in the variant cell lines analyzed here are the anomalies found in their chromosome constitution. These anomalies involved a change in chromosome number and the presence of double minute chromosomes. A third type of alteration, i.e., the appearance in one or more identifiable chromosomes of some variants of a homogeneously staining region (HSR) containing DHFR genes, analogous to that described in Chinese hamster and mouse MTX-resistant cell lines with stably amplified DHFR genes $(7,10,26)$, will be described elsewhere (H. Gay, B. Maurer, and G. Attardi, manuscript in preparation).

The occurrence of a duplicated set of chromosomes in most cells of the population, as has been observed here in some of the MTX-resis- 
tant variants, has not been reported previously in MTX-resistant cell lines. It seems likely that this chromosome duplication event, which occurred during the development of the resistance to MTX, conferred an advantage upon the cells undergoing it by rapidly doubling the DHFR gene complement and therefore, presumably, the cell content in DHFR. Consistent with this interpretation is the observation that, in variants with a duplicated set of chromosomes, the chromosome(s) containing an HSR is present in duplicate (Gay et al., in preparation).

All MTX-resistant variants investigated here exhibited the presence of double minute chromosomes. Such small, acentromeric elements have been described previously in many experimental and human tumors (for references, see references 3 and 21 ), where they are relatively stable in the absence of any known selective pressure. Recently, it has been reported that the double minutes from a mouse adrenocortical tumor contain amplified DNA sequences (14). Furthermore, the presence of double minutes has been described in several MTX-resistant mouse cell lines, and evidence has been presented strongly suggesting that these elements contain amplified DHFR genes (26). In the present work, the observation of a parallel loss of double minute chromosomes and DHFR activity in the variant $6 \mathrm{~A} 3$ is likewise consistent with the idea that, in this variant, such elements contain DHFR genes. Preliminary in situ hybridization experiments with a high-specific-activity probe derived from cloned DHFR cDNA have provided direct evidence of the presence of DHFRcoding sequences in double minute chromosomes from several MTX-resistant human variants (B. Maurer, unpublished observations). We do not know whether and to what extent the differences in size and stainability with orcein of the double minute chromosomes observed in cells of different human variants and among cells of the same variant and within the same metaphase can be accounted for by a variability in chromosome condensation. However, the reproducibility of the differences detected in the appearance of double minutes in the various resistant cell lines suggests the possibility that the amount of DNA can vary among different minutes. Such differences in DNA content may conceivably reflect a variation in the size or number (or both) of the amplified units contained in each minute. On the other hand, the observation that the double minute chromosomes vary greatly in number in different variants having a comparable degree of DHFR gene amplification (as estimated from the increase in DHFR activity [present work] and the increase in DHFR mRNA and DHFR specific sequences in the genome [unpublished observations]) with no obvious inverse relationship between their number and their size or stainability suggests that there must be another set of DHFR genes, representing a varied portion of the total, which is associated with the regular chromosomes. Recent observations indicate that, in some, but not all, variants, these chromosomal genes are located in HSRs associated with identifiable chromosomes (Gay et al., in preparation).

In previous studies on mouse MTX-resistant cell lines, the instability of the resistance in the absence of selective pressure has been found to be associated with the presence of double minute chromosomes; furthermore, in subpopulations of these unstable cell lines, a rough proportionality has been observed between the number of double minutes and the number of amplified DHFR genes (26). More recently, in uptake mutants of neuroblastoma cells, unstable drug resistance has also been correlated with the presence of double minute chromosomes (4). It has been hypothesized that, in the above-mentioned cell lines, unequal distribution of the double minutes at cell division and selective growth advantage for cells with lower numbers of these elements would account for the instability of the phenotype (17). The observations made in the present work may point to a more complicated situation in the human MTX-resistant variants. In fact, the average number of identifiable double minutes per cell in these variants has been found to be totally unrelated to the rate of loss of the excess DHFR activity in the absence of MTX. Our data suggest that instability of MTX resistance may also be associated with a chromosomal localization of the amplified units, and depend on a particular susceptibility of these chromosomal genes to be lost. Preliminary observations indicate that the presence of these unstable chromosomal genes in the human MTX-resistant variants is not obligatorily correlated with the occurrence of morphologically recognizable HSRs. An instability of MTX resistance associated with a reduction in size of the HSR present in an identifiable chromosome has been reported in a hamster cell line (J. L. Biedler and B. A. Spengler, J. Cell Biol. 70:117a, 1976).

\section{ACKNOWLEDGMENTS}

These investigations were supported by Public Health Service grants GM-11726 and T32 GM-07616 from the National Institutes of Health.

The HeLa BU25 cell line was generously provided by Saul Kit (Baylor University, Houston, Tex.). We are very grateful to Anne Chomyn, Carlo Morandi, Claus Doersen, and Barry Maurer for valuable discussions. The technical assistance of Arger Drew is gratefully acknowledged.

\section{LITERATURE CITED}

1. Alt, F. W., R. E. Kellems, J. R. Bertino, and R. T. Schimke. 1978. Selective multiplication of dihydrofolate reductase genes in methotrexate-resistant variants of cul- 
tured murine cells. J. Biol. Chem. 253:1357-1370.

2. Alt, F. W., R. E. Kellems, and R. T. Schimke. 1976. Synthesis and degradation of folate reductase in sensitive and methotrexate-resistant lines of S-180 cells. J. Biol. Chem. 251:3063-3074.

3. Barker, P. E., and T. C. Hsu. 1979. Double minutes in human carcinoma cell lines, with special reference to breast tumors. J. Natl. Cancer Inst. 62:257-261.

4. Baskin, R., R. N. Rosenberg, and V. Dev. 1981. Correlation of double-minute chromosomes with unstable multidrug cross-resistance in uptake mutants of neuroblastoma cells. Proc. Natl. Acad. Sci. U.S.A. 78:3654-3658.

5. Beach, L. R., and R. D. Palmiter. 1981. Amplification of the metallothioein-I gene in cadmium-resistant mouse cells. Proc. Natl. Acad. Sci. U.S.A. 78:2110-2114.

6. Biedler, J. L., A. M. Albrecht, D. J. Hutchison, and B. A. Spengler. 1972. Drug response, dihydrofolate reductase, and cytogenetics of amethopterin-resistant Chinese hamster cells in vitro. Cancer Res. 32:153-161.

7. Biedler, J. L., and B. A. Spengler. 1976. Metaphase chromosome anomaly: association with drug resistance and cell specific products. Science 91:185-187.

8. Bostock, C. J., E. M. Clark, N. G. L. Harding, P. M. Mounts, C. Tyler-Smith, V. Van Heyningen, and P. M. P. Walker. 1979. The development of resistance to methotrexate in a mouse melanoma cell line. I. Characterization of the dihydrofolate reductases and chromosomes in sensitive and resistant cells. Chromosoma 74:153-177.

9. Chang, S. E., and J. W. Littlefield. 1976. Elevated dihydrofolate reductase messenger RNA levels in methotrexate-resistant BHK cells. Cell 7:391-396.

10. Dolnick, B. J., R. J. Berenson, J. R. Bertino, R. J. Kaufman, J. H. Nunberg, and R. T. Schimke. 1978. Correlation of dihydrofolate reductase elevation with gene amplification in a homogeneously staining chromosomal region of L5178Y cells. J. Cell Biol. 83:394-402.

11. Fischer, G. A. 1961. Increased levels of folic acid reductase as a mechanism of resistance to amethopterin in leukemia cells. Biochem. Pharmacol. 7:75-77.

12. Flintof, W. F., S. V. Davidson, and L. Siminovitch. 1976. Isolation and partial characterization of three methotrexate-resistant phenotypes from Chinese hamster ovary cells. Somatic Cell Genet. 2:245-261.

13. Frearson, P. M., S. Kit, and D. R. Dubbs. 1966. Induction of dihydrofolate reductase activity by SV40 and polyoma virus. Cancer Res. 26:1653-1660.

14. George, D. L., and V. E. Powers. 1981. Cloning of DNA of double minutes of $\mathrm{Y} 1$ mouse adrenocortical tumor cells: evidence for gene amplification. Cell 24:117-123.

15. Hakala, M. T., S. F. Zakrewski, and C. A. Nichol. 1961. Relation of folic acid reductase to amethopterin resistance in cultured mammalian cells. J. Biol. Chem. 236:952-958.

16. Hängi, U. J., and J. W. Littlefield. 1976. Altered regulation of the rate of synthesis of dihydrofolate reductase in methotrexate-resistant hamster cells. J. Biol. Chem. 251:3075-3080.
17. Kaufman, R. J., P. C. Brown, and R. T. Schimke. 1979 Amplified dihydrofolate reductase genes in unstably methotrexate-resistant cells are associated with double minute chromosomes. Proc. Natl. Acad. Sci. U.S.A 76:5669-5673.

18. Kellems, R. E., F. W. Alt, and R. T. Schimke. 1976. Regulation of folate reductase synthesis in sensitive and methotrexate-resistant sarcoma S- 180 cells. In vitro translation and characterization of folate reductase mRNA. J. Biol. Chem. 251:6987-6993.

19. Kit, S., D. R. Dubbs, and P. M. Frearson. 1966. HeLa cells resistant to bromodeoxyuridine and deficient in thymidine kinase activity. Int. J. Cancer 1:19-30.

20. Laemmli, U. K. 1970. Cleavage of structural proteins during the assembly of the head of bacteriophage T4 Nature (London) 227:680-685.

21. Levan, A., G. Levan, and F. Milleman. 1977. Chromosomes and cancer. Hereditas 86:15-30.

22. Littlefield, J. W. 1969. Hybridization of hamster cells with high and low folate reductase activity. Proc. Natl. Acad. Sci. U.S.A. 62:88-95.

23. Melera, P. W., J. A. Lewis, J. L. Biedler, and C. Hession. 1980. Antifolate-resistant Chinese hamster cells. Evidence for dihydrofolate reductase gene amplification among independently derived sublines overproducing different dihydrofolate reductases. J. Biol. Chem. 255:70247028.

24. Mitchell, C. H., and G. Attardi. 1978. Cytoplasmic transfer of chloramphenicol resistance in a human cell line. Somatic Cell Genet. 4:737-744.

25. Morandi, C., and G. Attardi. 1981. Isolation and characterization of dihydrofolic acid reductase from methotrexate sensitive and resistant human cell lines. J. Biol. Chem. 256:10169-10175.

26. Nunberg, I. H., R. J. Kaufman, R. T. Schimke, G. Urlaub, and L. A. Chasin. 1978. Amplified dihydrofolate reductase genes are localized to a homogeneously staining region of a single chromosome in a methotrexate-resistant Chinese hamster ovary cell line. Proc. Natl. Acad. Sci. U.S.A. 75:5553-5556.

27. Perkins, J. P., B. L. Hillcoat, and J. R. Bertino. 1967. Dihydrofolate reductase from a resistant subline of the L12110 lymphoma. J. Biol. Chem. 242:4771-4776.

28. Pontén, J., F. Jensen, and H. Koprowski. 1963. Morphological and virological investigation of human tissue cultures transformed with SV40. J. Cell. Comp. Physiol. 61:145-154.

29. Wahl, G. M., R. A. Padgett, and G. R. Stark. 1979. Gene amplification causes overproduction of the first three enzymes of UMP synthesis in $\mathrm{N}$-(phosphoacetyl)-L-aspartate-resistant hamster cells. J. Biol. Chem. 254:86798689.

30. Wiedemann, L. M., and L. F. Johnson. 1979. Regulation of dihydrofolate reductase synthesis in an overproducing 3T6 cell line during transition from resting to growing state. Proc. Natl. Acad. Sci. U.S.A. 76:2818-2822. 